\title{
Ultra-low-dose chest CT protocol during the second wave of COVID-19 pandemic: a double-observer prospective study on 250 patients to evaluate its detection accuracy
}

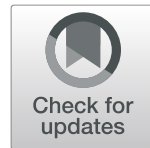

\author{
Ahmed Samir ${ }^{1 *}$ D, Reham Mohamed El-Husseiny², Rania Ahmed Sweed ${ }^{3}$, \\ Nermeen Abd El-Monsef Abd El-Maaboud ${ }^{1}$ and Mohamed Masoud ${ }^{1}$
}

\begin{abstract}
Background: While the second wave of COVID-19 pandemic almost reached its climax, unfortunately, new viral strains are rapidly spreading, and numbers of infected young adults are rising. Consequently, chest high-resolution computed tomography (HRCT) demands are increasing, regarding patients' screening, initial evaluation and follow up. This study aims to evaluate the detection accuracy of ultra-low-dose chest CT in comparison with the routine low-dose chest CT to reduce the irradiation exposure hazards.

Results: This study was prospectively conducted on 250 patients during the period from 15th December 2020 to 10th February 2021. All of the included patients were clinically suspected of COVID-19 infection. All patients were subjected to routine low-dose $(45 \mathrm{mAs})$ and ultra-low-dose $(22 \mathrm{mAs})$ chest $\mathrm{CT}$ examinations. Finally, all patients had confirmatory PCR swab tests and other dedicated laboratory tests. They included 149 males and 101 females (59.6\%:40.4\%). Their age ranged from 16 to 84 years (mean age $50 \pm 34$ SD). Patients were divided according to body weight; 104 patients were less than $80 \mathrm{~kg}$, and 146 patients were more than $80 \mathrm{~kg}$. HRCT findings were examined by two expert consultant radiologists independently, and data analysis was performed by other two expert specialist and consultant radiologists. The inter-observer agreement (IOA) was excellent (96-100\%). The ultra-low-dose chest CT reached 93.53-96.84\% sensitivity and 90.38-93.84\% accuracy. The signal-to-noise ratio (SNR) is 12.8:16.1; CTDlvol (mGy) =1.1 \pm 0.3, DLP (mGy $\mathrm{cm})=42.2 \pm 7.9$, mean effective dose $(\mathrm{mSv} / \mathrm{mGy} \mathrm{cm})=0.59$ and absolute cancer risk $=0.02 \times 10^{-4}$.
\end{abstract}

Conclusion: Ultra-low-dose HRCT can be reliably used during the second wave of COVID-19 pandemic to reduce the irradiation exposure hazards.

Keywords: COVID-19, Low dose, Ultra-low dose, HRCT

\section{Background}

Real-time polymerase chain reaction (PCR) remains the gold standard tool for the diagnosis of the Novel coronavirus disease (COVID-19) since it was first described in December 2019 and announced as a pandemic in February 2020 [1]. However, in mild cases with low viral load,

\footnotetext{
* Correspondence: Sweetjomana36@hotmail.com

'Department of Radiodiagnosis and Intervention, Faculty of Medicine,

University of Alexandria, Alexandria, Egypt

Full list of author information is available at the end of the article
}

many patients had false-negative swab tests [2]. The test also remains time-consuming, and PCR kits had not increased enough to face the increased number of patients all over the world [3, 4].

On the other hand, high-resolution computed tomography (HRCT) expressed more availability and more rapid results. Besides, HRCT sensitivity exceeded $90 \%$ in comparison with PCR sensitivity which could not exceed $75 \%$ [5]. Consequently, most of the publication since then recommended routine non-contrast HRCT of the

\section{Springer Open}

(0) The Author(s). 2021 Open Access This article is licensed under a Creative Commons Attribution 4.0 International License, which permits use, sharing, adaptation, distribution and reproduction in any medium or format, as long as you give appropriate credit to the original author(s) and the source, provide a link to the Creative Commons licence, and indicate if changes were made. The images or other third party material in this article are included in the article's Creative Commons licence, unless indicated otherwise in a credit line to the material. If material is not included in the article's Creative Commons licence and your intended use is not permitted by statutory regulation or exceeds the permitted use, you will need to obtain permission directly from the copyright holder. To view a copy of this licence, visit http://creativecommons.org/licenses/by/4.0/. 
chest for the evaluation of COVID-19 [6-8]. Low-dose CT was then introduced to decrease the ionizing irradiation risk of exposure [9].

In September 2019, the American Association of Physicists in Medicine (AAPM) suggested certain criteria for efficient low-dose CT during lung cancer screening among standard-sized persons (70-90 kg), including CTDIvol $\leq 3.0 \mathrm{mGy}$, DLP $\leq 75 \mathrm{mGy} \mathrm{cm}$ and effective dose $\leq 1.0 \mathrm{mSv}$ [10]. A dose of $50 \mathrm{mAs}$ was suggested before in 2016 for low-dose CT screening of intrathoracic abnormalities [11].

While the second wave of COVID-19 pandemic almost reached its climax, unfortunately, new viral strains are rapidly spreading, and numbers of infected young adults are rapidly rising. Hence, chest HRCT demands are increasing.

This study aims to evaluate the detection accuracy of ultra-low-dose chest $\mathrm{CT}$ in comparison with the routine low-dose chest CT during the assessment of COVID-19 patients in order to reduce the irradiation exposure hazards.

\section{Methods}

\section{Study population and design}

This study was prospectively conducted on 250 patients who were clinically suspected of COVID-19 infection during the period from 15th December 2020 to 10th February 2021. The study was approved by the Ethics Committee of our University hospital. Patient verbal consent was accepted by the Ethics Committee respecting absolute safety of non-invasive non-therapeutic procedure without additional personal risk or burden to the public health, also assuring full respect of both patient and medical record confidentiality. The authors emphasize on the fact that the overall radiation dose in both low- and ultra-low-dose CT examinations together remains much lower than single routine chest $\mathrm{CT}$ examination.

Patients included 149 males and 101 females (59.6\%: $40.4 \%$ ). Their age ranged from 16 to 84 years (mean age $50 \pm 34 \mathrm{SD}$ ). By definition of the American Association of Physicists in Medicine (AAPM), the standard bodyweight for an adult ranges from 70 to $90 \mathrm{~kg}$ [10]. Hence, patients were divided according to body weight: 104 patients were less than $80 \mathrm{~kg}$, and 146 patients were more than $80 \mathrm{~kg}$ (Mean weight $84.4 \pm 11.1 \mathrm{SD}$ ). This would eventually help to determine the accuracy of the suggested CT dose in relation to the variable body weight. The maximum weight reached in this study without image distortion was $107 \mathrm{~kg}$.

All patients were initially subjected to routine lowdose CT protocol (45 $\mathrm{mAs})$ [11], then all patients were examined by a new suggested ultra-low-dose CT examination $(22 \mathrm{mAs})$. Finally, all patients had confirmatory
PCR swab tests and other dedicated laboratory tests including; $\mathrm{CBC}$, CRP, D-dimer, serum ferritin, $\mathrm{LDH}$, procalcitonin, and sputum culture. Clinical and laboratory evaluation was performed by a single expert consultant pulmonologist.

Inclusion criteria were as follow: patients with clinical history of suspected COVID-19 infection including acute onset of either fever, cough, chest pain, dyspnea, body aches, sore throat, loss of smell sensation or loss of taste sensation.

Exclusion criteria were as follow: (1) Poor quality of CT images because of patients' tachypnea and motion artefacts and (2) non-available PCR test results or inconclusive final diagnosis.

\section{CT scanning (machines and protocols)}

Non-contrast CT chest examinations were performed in a single radiology center using a single multi-detector computed tomography machine: Aquilion 16, Canon Medical system Toshiba, Tustin, CA, USA. The scanning parameters and the CT dosing measurements of both low-dose and ultra-low-dose CT protocols exactly followed the guidelines of AAPM [10]. They are detailed in (Table 1) in correlation to the body weight. Adaptive Iterative Dose Reduction (AIDR) was used in all examinations to reduce the irradiation dose while maintaining an acceptable image quality. Smooth images were obtained at $40 \%$.

\section{CT scanning (radiation dose calculation and cancer risk estimation)}

The effective dose in millisievert (mSv) was calculated according to the American Association of Physicists in

Table 1 Scanning parameters for the initial "low-dose" and suggested "ultra-low-dose" CT protocol according to body weight

\begin{tabular}{|c|c|c|c|c|}
\hline & \multicolumn{4}{|c|}{ CT protocol } \\
\hline & \multicolumn{2}{|c|}{$\begin{array}{l}\text { Initial } \\
\text { "Iow dose" }\end{array}$} & \multicolumn{2}{|c|}{$\begin{array}{l}\text { Suggested } \\
\text { "ultra-low dose" }\end{array}$} \\
\hline & \multicolumn{4}{|c|}{ Body weight } \\
\hline & $<80 \mathrm{~kg}$ & $\geq 80 \mathrm{~kg}$ & $<80 \mathrm{~kg}$ & $\geq 80 \mathbf{~ k g}$ \\
\hline \multicolumn{5}{|l|}{ Scanning parameters } \\
\hline kV & 120 & 120 & 120 & 120 \\
\hline $\mathrm{mA}$ & 60 & 60 & 30 & 30 \\
\hline Rotation time & 0.75 & 0.75 & 0.75 & 0.75 \\
\hline $\mathrm{mAs}(\mathrm{mA} \times$ time $)$ & 45 & 45 & 22 & 22 \\
\hline Pitch & 1.4 & 1.4 & 1.4 & 1.4 \\
\hline Eff mAs (mAs/pitch) & 32 & 32 & 16 & 16 \\
\hline Slice thickness (mm) & 5 & 5 & 5 & 5 \\
\hline Slice thickness recon & 1.5 & 1.5 & 1.5 & 1.5 \\
\hline Field of view (FOV) & 350 & 350 & 350 & 350 \\
\hline Matrix size & $512 \times 512$ & $512 \times 512$ & $512 \times 512$ & $512 \times 512$ \\
\hline
\end{tabular}


Medicine by multiplying the total dose length product (DLP) by conversion coefficient $(0.014 \mathrm{mSv} / \mathrm{mGy} \mathrm{cm})$ [12]. The mean risk for developing cancer in populations who were exposed to irradiation (absolute cancer risk) is calculated by multiplying the forementioned effective dose by the risk coefficient $\left(0.041 \mathrm{~Sv}^{-1}\right)$ [13].

\section{CT scanning (data evaluation)}

The HRCT findings of the low-dose and ultra-low-dose CT examinations were assessed among two groups of patients (A: less than $80 \mathrm{~kg}$ and B: more than $80 \mathrm{~kg}$ ) by two expert consultant radiologists independently, and data analysis was performed by other two expert radiologists (their experience ranged 6-14 years). They were informed of the patients' clinical history.

The universal HRCT features of COVID-19 were respected which include ground-glass opacities (GGOs), solid nodules with GG halo, consolidative changes, fibro-atelectatic changes and sub-pleural curvilinear bands, crazy-paving pattern (GG admixed with septal thickening) and tree in bud nodules.

The HRCT image evaluation was performed using multi-planar reconstruction (axial, sagittal and coronal planes). The minimum intensity projection (Min-IP) reconstruction was used for adequate evaluation of the ground glass attenuation. The maximum intensity projection (MIP) reconstruction was used for evaluation of the septal thickening, crazy paving pattern, and tree in bud nodules.

The minimum attenuation/density of the pathological regions was measured in both low-dose and ultra-lowdose CT examinations among both groups of patients using the Hounsfield unit $(\mathrm{Hu})$. This would eventually help to detect not only the accuracy of the ultra-lowdose CT protocol but also the percentage of error regarding the lung attenuation.

The image quality was assessed objectively using the signal-to-noise ratio (SNR). It is calculated through the following formula [SNR = Density of air / SD of air] [14]. The standard deviation (SD) of the region of interest (ROI) is measured within the tracheal lumen just above the level of the aortic arch. It is calculated three times in the lung window setting (window level $=-700$ $\mathrm{HU}$; window width $=1500 \mathrm{HU}$ ), then the mean value is estimated. Certain ROI surface area is unified $\left(0.3 \mathrm{~cm}^{2}\right)$ [15]. By definition, the higher the signal-to-noise ratio, the better the resolution (Fig. 1) [16].

\section{Statistical analysis}

The prevalence rate of each HRCT finding (isolated or mixed) was estimated as the percentage of patients with each abnormal CT finding. This was done by each observer for both groups of patients regarding both lowdose and ultra-low-dose CT examinations.

Similarly, the prevalence rate of the maximum attenuation of the pathological lesions was also estimated.

Cohen's Kappa test was utilized to calculate the "InterObserver Agreement" (IOA) coefficient regarding each HRCT characteristic and lung attenuation.

An online calculator (https://www.medcalc.org/calc/ diagnostic_test.php) was utilized to detect the mean value and 95\% confidence interval $(95 \% \mathrm{CI})$ regarding the sensitivity, specificity, positive predictive value (PPV), negative predictive value, positive likelihood ratio, negative likelihood ratio, and accuracy of both low-dose and ultra-low-dose CT protocols.

\section{Results}

CT dose calculations and cancer risk estimation (Table 2)

The main differentiating parameter between the routine low-dose CT protocol which was previously implemented for screening of lung cancer and the new ultralow-dose CT which is suggested for assessment of COVD-19 pneumonia was the intensity of the irradiation. At the low-dose CT, $\mathrm{mA}$ was 60 , $\mathrm{mAs}$ was 45 and Eff $\mathrm{mAs}$ was 32. In ultra-low-dose CT, the $\mathrm{mA}$ was 30 ,

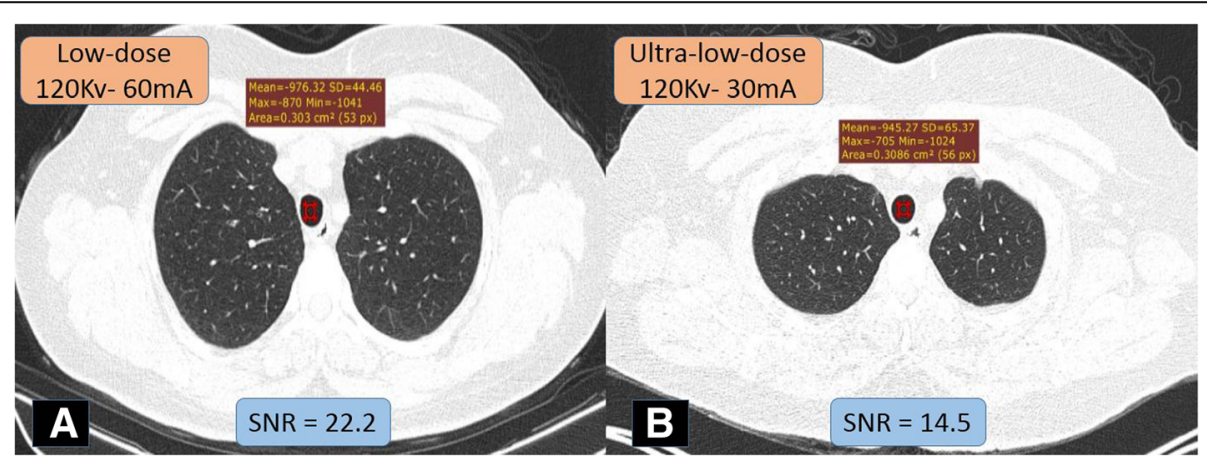

Fig. 1 Image quality at highest and lowest SNR; measured at axial chest CT cuts/lung window (- 700:1500) within the tracheal lumen immediately above the aortic arch at standardized $0.3 \mathrm{~cm}^{2} \mathrm{ROI}(\mathrm{SNR}=$ mean attenuation/SD). a Low-dose CT with higher SNR in a 77-kg patient and $\mathbf{b}$ ultra-low-dose CT with lower SNR in a 85-kg patient; there is no significant blurring at lung image; however, mild blurring is noted at the shadow of the thoracic cage muscles 
Table 2 CT dosing measurements and image quality for the initial "low-dose" and suggested "ultra-low dose" CT protocols according to body weight

\begin{tabular}{|c|c|c|c|c|}
\hline & \multicolumn{4}{|l|}{ CT protocol } \\
\hline & \multicolumn{2}{|l|}{$\begin{array}{l}\text { Initial } \\
\text { "low dose" }\end{array}$} & \multicolumn{2}{|c|}{$\begin{array}{l}\text { Suggested } \\
\text { "ultra-low dose" }\end{array}$} \\
\hline & \multicolumn{4}{|c|}{ Body weight } \\
\hline & $<80 \mathbf{k g}$ & $\geq 80 \mathbf{~ k g}$ & $<80$ kg & $\geq 80 \mathbf{~ k g}$ \\
\hline \multicolumn{5}{|l|}{ CT dose } \\
\hline CTDIvol (mGy) & $1.6 \pm 0.4$ & $1.6 \pm 0.4$ & $1.1 \pm 0.3$ & $1.1 \pm 0.3$ \\
\hline DLP (mGy cm) & $60.9 \pm 9.5$ & $60.9 \pm 9.5$ & $42.2 \pm 7.9$ & $42.2 \pm 7.9$ \\
\hline Mean effective dose (mSv/mGy cm) & 0.85 & 0.85 & 0.59 & 0.59 \\
\hline Absolute cancer risk & $0.03 \times 10^{-4}$ & $0.03 \times 10^{-4}$ & $0.02 \times 10^{-4}$ & $0.02 \times 10^{-4}$ \\
\hline \multicolumn{5}{|l|}{ Image quality } \\
\hline Objective image noise (SD) & $39.1-44.4$ & $48.3-54.1$ & $59.5-61$ & $65.9-73.8$ \\
\hline Signal-to-noise ratio (SNR) & $21.2-24.4$ & $17.5-19.8$ & $15.3-16.1$ & $12.8-14.5$ \\
\hline
\end{tabular}

mAs was 22 and Eff mAs was 16. Other parameters were similar. Consequently, there was a decrease in the CT dose measurements. CTDIvol dropped from $1.6 \pm 0.4$ mGy to $1.1 \pm 0.3 \mathrm{mGy}$. DLP dropped from $60.9 \pm 9.5$ to $42.2 \pm 7.9 \mathrm{mGy} \mathrm{cm}$. The mean effective dose also dropped from 0.85 to $0.59 \mathrm{mSv} / \mathrm{mGy} \mathrm{cm}$. Absolute cancer risk consequently dropped from $0.03 \times 10^{-4}$ to 0.02 $\times 10^{-4}$.

\section{Image quality (objective SNR) (Table 2)}

The image quality was minimally decreased in the ultralow-dose CT protocol. The signal-to-noise ratio (SNR) in the ultra-low-dose CT was lower than that in the low-dose CT (12.8-16.1 compared with 17.5-24.4 respectively). This almost did not impact the diagnostic efficacy of CT as detailed later on.

\section{Prevalence of HRCT findings (Table 3)}

Ground-glass opacities were the most common findings among our patients. They were found alone in 173 patients (69.2\%). They were found also surrounding a solid nodule (ground-glass halo sign) among 49 patients (19.6\%) and associated with interlobular septal thickening (crazy paving pattern) also among 49 patients (19.6\%). Consolidative changes with or without groundglass opacities were detected among 84 patients (33.6\%). The CT attenuation of these pathological CT findings ranged from +40 to $-750 \mathrm{HU}$. The predominant CT

Table 3 Distribution of HRCT findings (CT patterns and CT density) at low dose (45 mAs) and ultra-low dose (22 mAs) among 228 patients with more or less than 80-kg body weight, performed by two separate observers

\begin{tabular}{|c|c|c|c|c|c|c|c|c|c|c|c|c|c|c|c|c|}
\hline \multirow[b]{3}{*}{ HRCT findings: } & \multicolumn{6}{|c|}{ Observer (1) } & \multicolumn{6}{|c|}{ Observer (2) } & \multicolumn{4}{|c|}{ Inter-observer agreement (IOA) } \\
\hline & \multicolumn{3}{|c|}{$W$ (weight) $<80 \mathrm{Kg}$} & \multicolumn{3}{|c|}{$W \geq 80 \mathrm{Kg}$} & \multicolumn{3}{|c|}{$W<80 \mathrm{Kg}$} & \multicolumn{3}{|c|}{$\mathrm{W} \geq 80 \mathrm{Kg}$} & \multicolumn{2}{|c|}{$W<80 \mathrm{Kg}$} & \multicolumn{2}{|c|}{$W \geq 80 \mathrm{Kg}$} \\
\hline & $\begin{array}{c}45 \\
\mathrm{mAs}\end{array}$ & $\begin{array}{c}22 \\
\text { mAs }\end{array}$ & $\begin{array}{c}\% \\
22 \mathrm{mAs} \\
145 \mathrm{mAs}\end{array}$ & $\begin{array}{c}45 \\
\mathrm{mAs}\end{array}$ & $\begin{array}{c}22 \\
\text { mAs }\end{array}$ & $\begin{array}{c}\% \\
22 \mathrm{mAs} \\
145 \mathrm{mAs}\end{array}$ & $\begin{array}{c}45 \\
\mathrm{mAs}\end{array}$ & $\begin{array}{c}22 \\
\mathrm{mAs}\end{array}$ & $\begin{array}{c}\% \\
22 \mathrm{mAs} \\
145 \mathrm{mAs}\end{array}$ & $\begin{array}{c}45 \\
\mathrm{mAs}\end{array}$ & $\underset{\mathrm{mAs}}{22}$ & $\begin{array}{c}\% \\
22 \mathrm{mAs} \\
145 \mathrm{mAs}\end{array}$ & $\begin{array}{c}45 \\
\mathrm{mAs}\end{array}$ & $\begin{array}{c}22 \\
\text { mAs }\end{array}$ & $\begin{array}{c}45 \\
\text { mAs }\end{array}$ & $\begin{array}{c}22 \\
\text { mAs }\end{array}$ \\
\hline \multicolumn{17}{|l|}{ According to HRCT pattern: } \\
\hline \multicolumn{17}{|l|}{ * Ground glass (GG): } \\
\hline - Nodules $(<1 \mathrm{~cm})$ : & 7 & 7 & $100 \%$ & 17 & 13 & $77 \%$ & 6 & 6 & $100 \%$ & 16 & 15 & $94 \%$ & $86 \%$ & $86 \%$ & $94 \%$ & $87 \%$ \\
\hline - Nodules $(1-3 \mathrm{~cm})$ : & 12 & 12 & $100 \%$ & 25 & 25 & $100 \%$ & 13 & 13 & $100 \%$ & 26 & 26 & $100 \%$ & $92 \%$ & $92 \%$ & $96 \%$ & $96 \%$ \\
\hline - Patches (> 3cm): & 49 & 49 & $100 \%$ & 29 & 29 & $100 \%$ & 52 & 52 & $100 \%$ & 27 & 27 & $100 \%$ & $94 \%$ & $94 \%$ & $93 \%$ & $93 \%$ \\
\hline $\begin{array}{l}\text { - Diffuse (>50\%) lobar } \\
\text { or lung involvement: }\end{array}$ & 11 & 11 & $100 \%$ & 17 & 17 & $100 \%$ & 9 & 9 & $100 \%$ & 19 & 19 & $100 \%$ & $82 \%$ & $82 \%$ & $89 \%$ & $89 \%$ \\
\hline $\begin{array}{l}\text { * Solid nodule with GG } \\
\text { halo: }\end{array}$ & 22 & 22 & $100 \%$ & 22 & 20 & $91 \%$ & 25 & 25 & $100 \%$ & 24 & 23 & $96 \%$ & $88 \%$ & $88 \%$ & $92 \%$ & $87 \%$ \\
\hline $\begin{array}{l}\text { * Consolidations (with or } \\
\text { without GG): }\end{array}$ & 38 & 38 & $100 \%$ & 42 & 42 & $100 \%$ & 42 & 42 & $100 \%$ & 42 & 42 & $100 \%$ & $90 \%$ & $90 \%$ & $100 \%$ & $100 \%$ \\
\hline $\begin{array}{l}\text { Fibro-atelectatic } \\
\text { changes and curvilinear } \\
\text { bands: }\end{array}$ & 32 & 32 & $100 \%$ & 40 & 40 & $100 \%$ & 30 & 30 & $100 \%$ & 39 & 39 & $100 \%$ & $94 \%$ & $94 \%$ & $98 \%$ & $98 \%$ \\
\hline * Crazy-paving pattern: & 23 & 23 & $100 \%$ & 26 & 26 & $100 \%$ & 18 & 18 & $100 \%$ & 24 & 24 & $100 \%$ & $78 \%$ & $78 \%$ & $92 \%$ & $92 \%$ \\
\hline * Tree in bud nodules: & 0 & 0 & - & 1 & 1 & $100 \%$ & 0 & 0 & - & 1 & 1 & $100 \%$ & - & - & $100 \%$ & $100 \%$ \\
\hline \multicolumn{17}{|c|}{ According to lowest Hu (lowest attenuation or density value): } \\
\hline$-700:-750 \mathrm{Hu}$ & 4 & 4 & $100 \%$ & 4 & 4 & $100 \%$ & 5 & 5 & $100 \%$ & 4 & 4 & $100 \%$ & $80 \%$ & $80 \%$ & $100 \%$ & $100 \%$ \\
\hline$-600:-500 \mathrm{Hu}$ & 9 & 9 & $100 \%$ & 10 & 7 & $70 \%$ & 10 & 10 & $100 \%$ & 10 & 9 & $90 \%$ & $90 \%$ & $90 \%$ & $100 \%$ & $78 \%$ \\
\hline$-500:-400 \mathrm{Hu}$ & 18 & 18 & $100 \%$ & 5 & 3 & $60 \%$ & 17 & 17 & $100 \%$ & 5 & 4 & $80 \%$ & $94 \%$ & $94 \%$ & $100 \%$ & $75 \%$ \\
\hline$-400:-300 \mathrm{Hu}$ & 52 & 52 & $100 \%$ & 105 & 104 & $99 \%$ & 51 & 51 & $100 \%$ & 105 & 105 & $100 \%$ & $99 \%$ & $99 \%$ & $100 \%$ & $99 \%$ \\
\hline$-300:-200 \mathrm{Hu}$ & 5 & 5 & $100 \%$ & 7 & 7 & $100 \%$ & 7 & 7 & $100 \%$ & 7 & 7 & $100 \%$ & $71 \%$ & $71 \%$ & $100 \%$ & $100 \%$ \\
\hline$-200:-100 \mathrm{Hu}$ & 2 & 2 & $100 \%$ & 3 & 3 & $100 \%$ & 2 & 2 & $100 \%$ & 4 & 4 & $100 \%$ & $100 \%$ & $100 \%$ & $75 \%$ & $75 \%$ \\
\hline$-100: 40 \mathrm{Hu}$ & 2 & 2 & $100 \%$ & 2 & 2 & $100 \%$ & 2 & 2 & $100 \%$ & 1 & 1 & $100 \%$ & $100 \%$ & $100 \%$ & $50 \%$ & $50 \%$ \\
\hline Collectively & 92 & 92 & $100 \%$ & 136 & 130 & $96 \%$ & 92 & 92 & $100 \%$ & 136 & 134 & $\mathbf{9 9 \%}$ & $100 \%$ & $100 \%$ & $100 \%$ & $97 \%$ \\
\hline
\end{tabular}


attenuation among these CT findings ranged from -300 to $-400 \mathrm{HU}$ (157 patients/62.8\%).

\section{Detection ability of HRCT findings of COVID-19 and their CT attenuation (Table 3)}

\section{Among 104 patients with $<80-\mathrm{kg}$ body weight}

In comparison with the low-dose CT, the ultra-low-dose CT protocol similarly detected all HRCT findings of COVID-19 (including the ground-glass opacities, consolidations, fibrotic changes, Atoll sign and crazy paving pattern), as well as their ranges of CT attenuation $(+40$ to $-750 \mathrm{HU})$. The inter-observer agreement was excellent (100\%) (Figs. 2 and 3).

\section{Among 146 patients with $\geq 80-\mathrm{kg}$ body weight}

In comparison with the low-dose CT, the ultra-low-dose CT protocol only showed lower efficacy regarding detection of small GG nodules $<1 \mathrm{~cm}$ and nodules with ground-glass halo sign (ranging from 77 to $94 \%$ and 91 to $96 \%$ among both observers respectively). The CT attenuation of these lesions ranged from -300 to -600 HU. Otherwise, no absolute differences were found regarding the detection of the rest of the HRCT findings and their ranges of $\mathrm{CT}$ attenuation. Finally, the interobserver agreement was collectively excellent (96-100\%) (Figs. 4, 5 and 6).
Final diagnosis and statistical differences between lowdose and ultra-low-dose CT

A multi-compartmental flow chart (Fig. 7) is summarizing the CT results for both observers and final diagnoses after PCR results; regarding low-dose and ultra-low-dose CT examination for patients less than and more than 80-kg body weight.

Collectively the ultra-low-dose chest CT reached 93.53-96.84\% sensitivity and $90.38-93.84 \%$ accuracy in comparison with the low-dose CT which showed 96.8497.84\% sensitivity and $90.38-95.21 \%$ accuracy.

\section{Among 104 patients with < 80-kg body weight (Table 4)}

No differences were found between both observers at both low-dose and ultra-low-dose CT protocols regarding the final diagnosis. Ninety-two patients (88.5\%) were truly positive and confirmed by PCR to have COVID-19. On the other hand, only 3 patients (3\%) were false negative. Consequently, both CT protocols showed same statistical results: sensitivity (mean $=96.84 \%$ and CI 95\% $=91.05$ to $99.34 \%$ ) and accuracy (mean $=90.38 \%$ and $\mathrm{CI}$ $95 \%=83.03$ to $95.29 \%)$.

CT specificity was equally low (22.22\%) for both lowdose and ultra-low-dose CT as 7/99 patients showed false-positive CT results with negative PCR swab tests and alternative diagnoses (two patients had fungal pneumonia, and five patients had aspiration pneumonia).

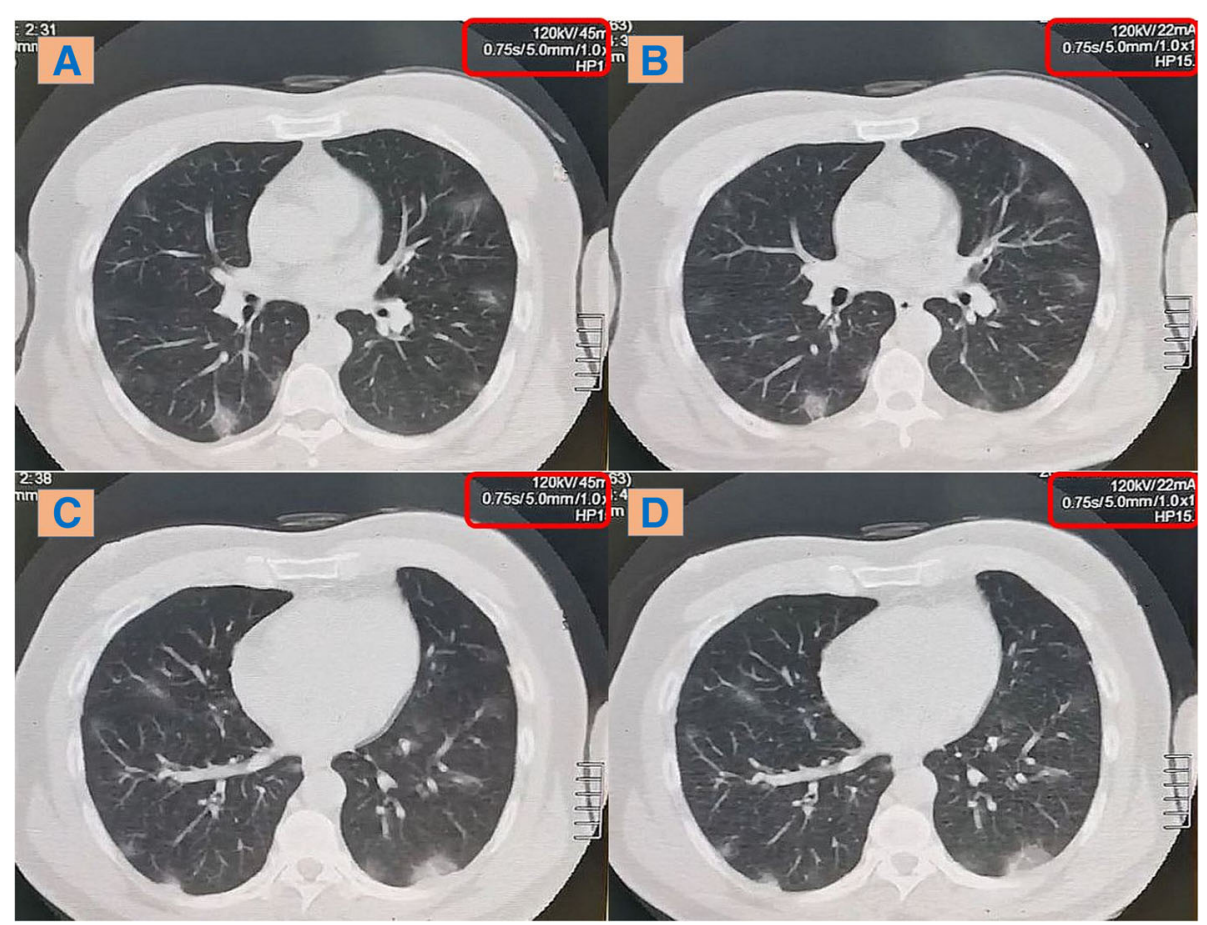

Fig. 2 A 72-kg male patient complaining from anosmia and sore throat; axial CT chest lung window showing bilateral sub-pleural scattered ground-glass patches. a \& c Low-dose CT. b \& d Ultra-low-dose CT 


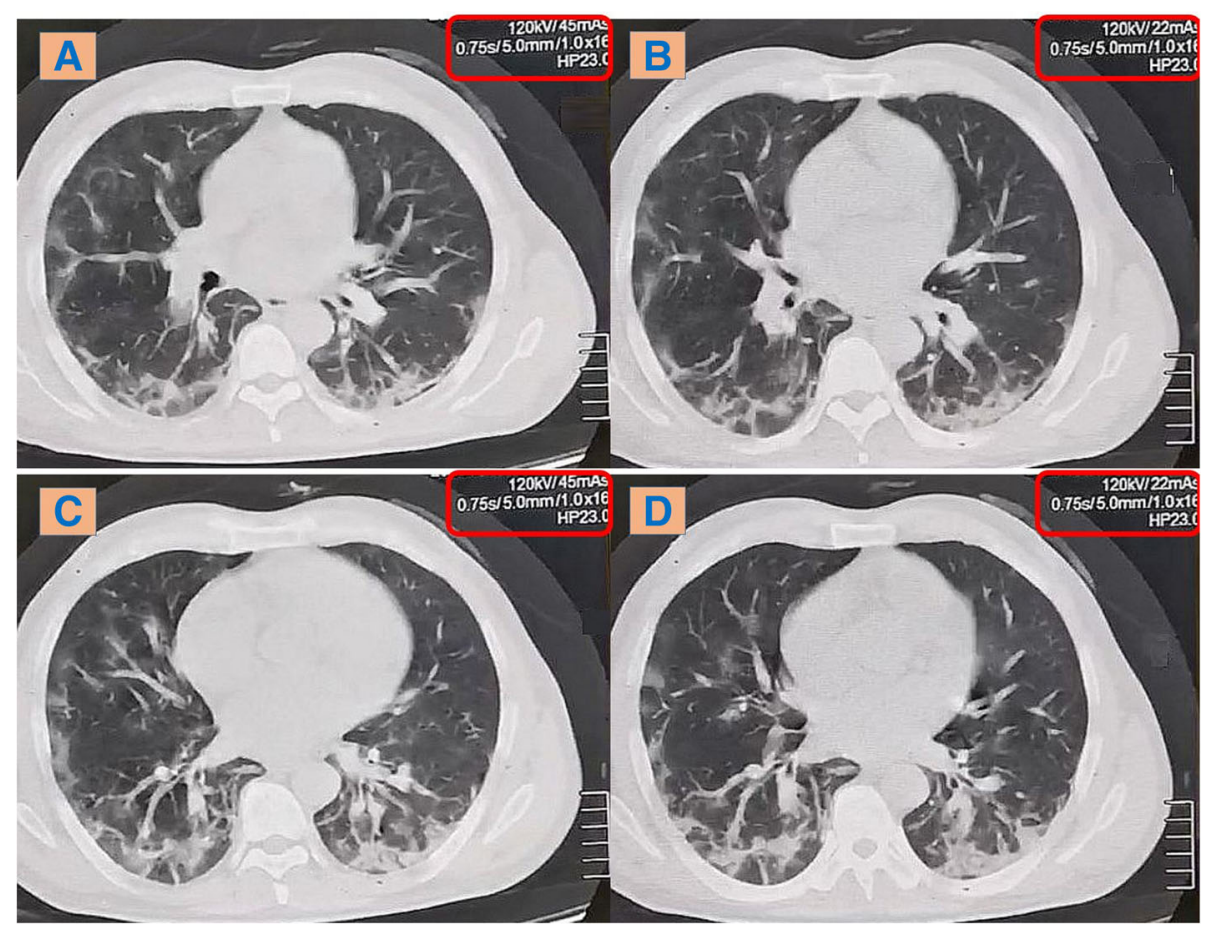

Fig. 3 A 75-kg male patient complaining from fever, cough and dyspnea; axial CT chest lung window showing bilateral sub-pleural scattered ground-glass patches with fibro-atelectatic changes. a \& c Low-dose CT. b \& d Ultra-low-dose CT

\section{Among 146 patients with $\geq 80-\mathrm{kg}$ body weight (Table 5)}

Observer 1 truly detected 130 patients using ultralow-dose CT compared with 136 patients using lowdose CT. Six cases were furtherly missed using the ultra-lose-dose CT. Consequently the low-dose CT showed sensitivity (mean $=97.84 \%$ and $\mathrm{CI} 95 \%=$ 93.82 to $99.55 \%$ ) and accuracy (mean $=95.21 \%$ and CI $95 \%=90.37$ to $98.05 \%$ ), while the ultra-low-dose CT showed sensitivity (mean $=93.53 \%$ and CI 95\% = 88.06 to $97.00 \%$ ) and accuracy (mean $=91.10 \%$ and CI $95 \%=85.26$ to $95.17 \%)$.
Meanwhile, observer 2 truly detected 134 patients using ultra-low-dose CT compared with 136 patients using lowdose CT, while only two cases were furtherly missed using the ultra-low-dose CT. Consequently the low-dose CT showed sensitivity (mean $=97.84 \%$ and CI $95 \%=93.82$ to 99.55\%) and accuracy (mean $=95.21 \%$ and CI 95\% $=90.37$ to $98.05 \%$ ), while the ultra-low-dose CT showed sensitivity ( mean $=96.40 \%$ and CI 95\% $=91.81$ to $98.82 \%$ ) and accuracy (mean $=93.84 \%$ and CI $95 \%=88.62$ to $97.14 \%$ ).

CT specificity was equally low (42.86\%) for both lowdose and ultra-low-dose CT as 4/146 patients showed false-

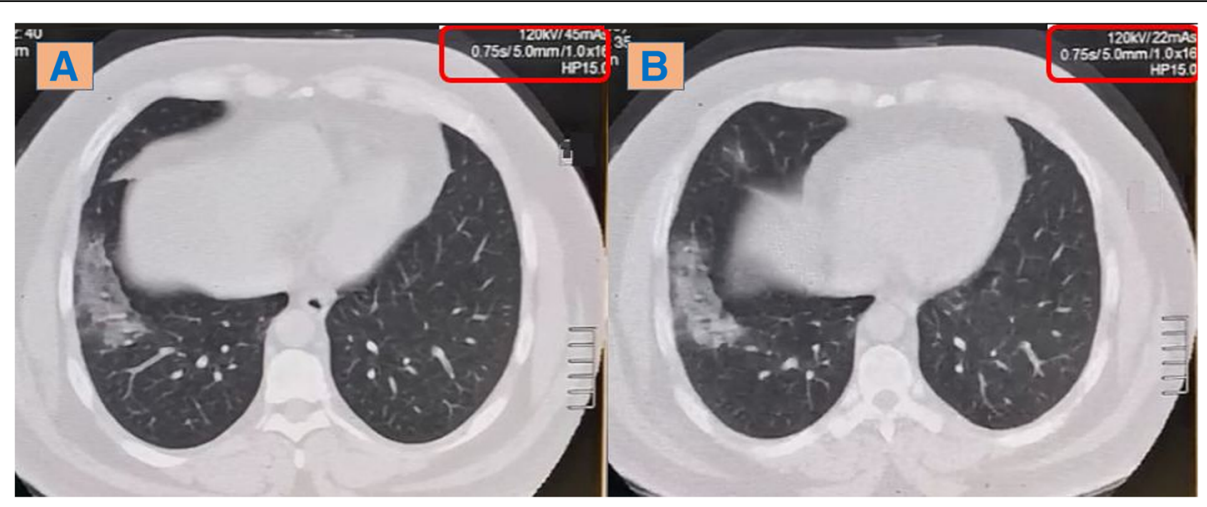

Fig. 4 A 83-kg male patient complaining from fever and cough; axial CT chest lung window showing right lower lobar single ground-glass patch. a Low-dose CT. b Ultra-low-dose CT 


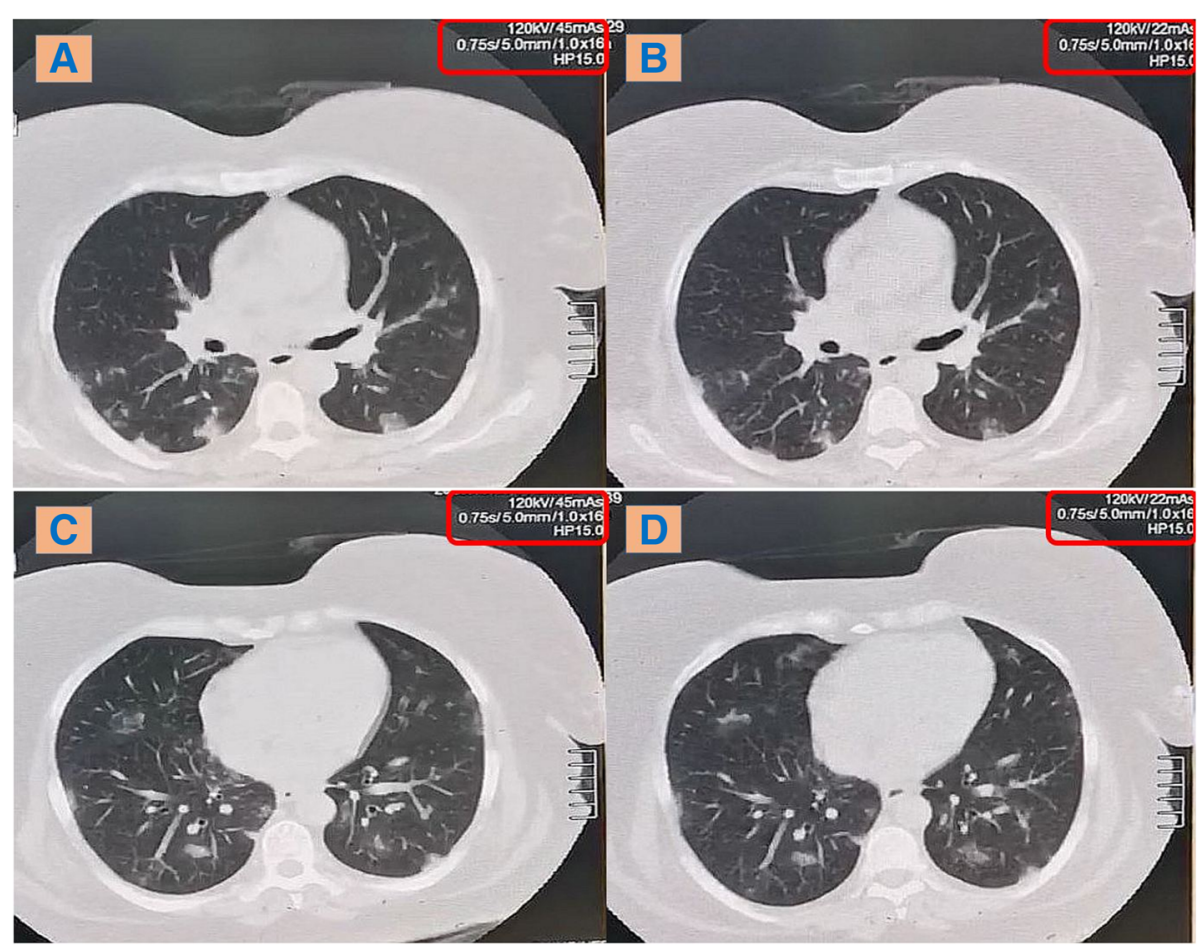

Fig. 5 A 95-kg female patient complaining from fever and dyspnea; axial CT chest lung window showing bilateral sub-pleural scattered groundglass patches. a \& c Low-dose CT. b \& d Ultra-low-dose CT

positive CT results with negative PCR swab tests and alternative diagnoses (two patients had exacerbated interstitial pneumonia, and two patients had aspiration pneumonia).

Comparison with other $\mathrm{CT}$ protocols is demonstrated in Table 6, regarding patient groups, dose parameters and final $\mathrm{CT}$ protocol results.

\section{Discussion}

The second wave and even further crisis of COVID-19 pandemic are striking the world with increased demands for chest CT imaging [21].
Similar to Chung et al. [22] and Song et al. [23], pure ground-glass opacities were the most common HRCT finding of COVID-19 in this study. According to Xia et al. [17], a solitary pure GG nodule could be the first sign of COVID-19 infection. This eventually increased the challenge during the lowering of the CT dose.

According to Kubo et al. [11], the DLP was $764.3 \mathrm{mGy}$ $\mathrm{cm}$, the mean effective dose was $10.7 \mathrm{mSv} / \mathrm{mGy} \mathrm{cm}$, and absolute cancer risk was $0.4 \times 10^{-4}$. These estimated radiation doses are 12.5:13.3 and 18.1:20 times more than that of the low-dose and the ultra-low-dose CT protocols in this study respectively. Additionally, the DLP and

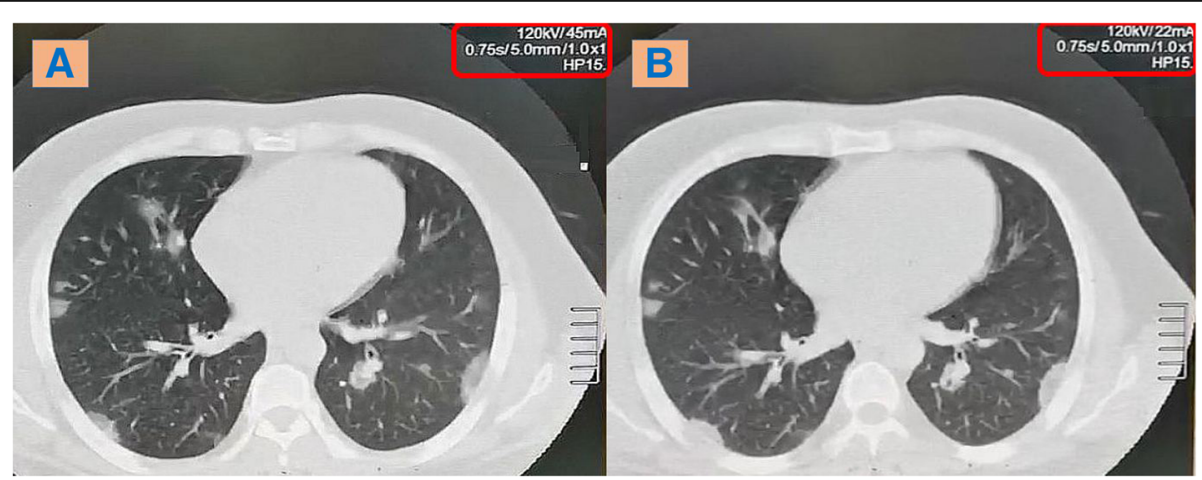

Fig. 6 An 85-kg male patient complaining from fever and cough; axial CT chest lung window showing bilateral sub-pleural scattered groundglass patches. a Low-dose CT. b Ultra-low-dose CT 


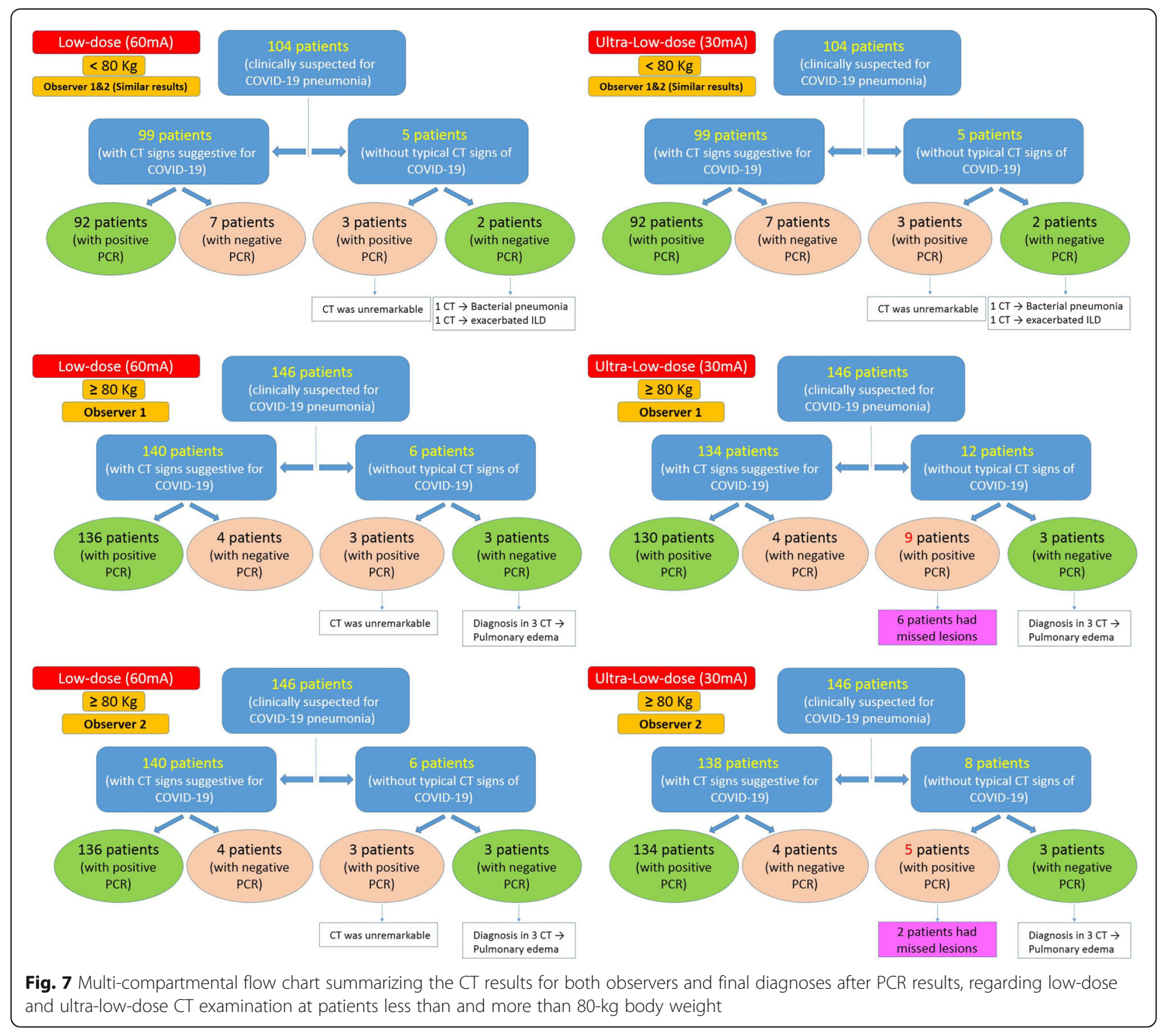

Table 4 Summary of statistical results for "low-dose" and "ultra-low-dose" CT protocols in patients (< 80-kg body weight)

\begin{tabular}{|c|c|c|c|c|c|c|c|c|}
\hline \multirow[t]{3}{*}{ Statistical results } & \multicolumn{4}{|c|}{ Low-dose CT (45 mAs) } & \multicolumn{4}{|c|}{ Ultra-low-dose CT (22 mAs) } \\
\hline & \multicolumn{2}{|c|}{ Observer 1} & \multicolumn{2}{|c|}{ Observer 2} & \multicolumn{2}{|c|}{ Observer 1} & \multicolumn{2}{|c|}{ Observer 2} \\
\hline & Value & $95 \% \mathrm{Cl}^{\mathrm{a}}$ & Value & $95 \% \mathrm{Cl}$ & Value & $95 \% \mathrm{Cl}$ & Value & $95 \% \mathrm{Cl}$ \\
\hline Sensitivity & $96.84 \%$ & 91.05 to $99.34 \%$ & $96.84 \%$ & 91.05 to $99.34 \%$ & $96.84 \%$ & 91.05 to $99.34 \%$ & $96.84 \%$ & 91.05 to $99.34 \%$ \\
\hline Specificity & $22.22 \%$ & 2.81 to $60.01 \%$ & $22.22 \%$ & 2.81 to $60.01 \%$ & $22.22 \%$ & 2.81 to $60.01 \%$ & $22.22 \%$ & 2.81 to $60.01 \%$ \\
\hline Positive predictive value (PPV) & $92.93 \%$ & 90.25 to $94.92 \%$ & $92.93 \%$ & 90.25 to $94.92 \%$ & $92.93 \%$ & 90.25 to $94.92 \%$ & $92.93 \%$ & 90.25 to $94.92 \%$ \\
\hline Negative predictive value (NPV) & $40.00 \%$ & 11.31 to $77.70 \%$ & $40.00 \%$ & 11.31 to $77.70 \%$ & $40.00 \%$ & 11.31 to $77.70 \%$ & $40.00 \%$ & 11.31 to $77.70 \%$ \\
\hline Positive likelihood ratio & 1.25 & 0.88 to 1.77 & 1.25 & 0.88 to 1.77 & 1.25 & 0.88 to 1.77 & 1.25 & 0.88 to 1.77 \\
\hline Negative likelihood ratio & 0.14 & 0.03 to 0.74 & 0.14 & 0.03 to 0.74 & 0.14 & 0.03 to 0.74 & 0.14 & 0.03 to 0.74 \\
\hline Accuracy & $90.38 \%$ & 83.03 to $95.29 \%$ & $90.38 \%$ & 83.03 to $95.29 \%$ & $90.38 \%$ & 83.03 to $95.29 \%$ & $90.38 \%$ & 83.03 to $95.29 \%$ \\
\hline
\end{tabular}


Table 5 Summary of statistical results for "low-dose" and "ultra-low-dose" CT protocols in patients ( $\geq$ 80-kg body weight)

\begin{tabular}{|c|c|c|c|c|c|c|c|c|}
\hline \multirow[t]{3}{*}{ Statistical results: } & \multicolumn{4}{|c|}{ Low-dose CT (45 mAs) } & \multicolumn{4}{|c|}{ Ultra-low-dose CT (22 mAs) } \\
\hline & \multicolumn{2}{|c|}{ Observer 1} & \multicolumn{2}{|c|}{ Observer 2} & \multicolumn{2}{|c|}{ Observer 1} & \multicolumn{2}{|c|}{ Observer 2} \\
\hline & Value & $95 \% \mathrm{Cl}^{\mathrm{a}}$ & Value & $95 \% \mathrm{Cl}$ & Value & $95 \% \mathrm{Cl}$ & Value & $95 \% \mathrm{Cl}$ \\
\hline Sensitivity & $97.84 \%$ & 93.82 to $99.55 \%$ & $97.84 \%$ & 93.82 to $99.55 \%$ & $93.53 \%$ & 88.06 to $97.00 \%$ & $96.40 \%$ & 91.81 to $98.82 \%$ \\
\hline Specificity & $42.86 \%$ & 9.90 to $81.59 \%$ & $42.86 \%$ & 9.90 to $81.59 \%$ & $42.86 \%$ & 9.90 to $81.59 \%$ & $42.86 \%$ & 9.90 to $81.59 \%$ \\
\hline Positive predictive value (PPV) & $97.14 \%$ & 94.71 to $98.48 \%$ & $97.14 \%$ & 94.71 to $98.48 \%$ & $97.01 \%$ & 94.47 to $98.41 \%$ & $97.10 \%$ & 94.63 to $98.45 \%$ \\
\hline Negative predictive value (NPV) & $50.00 \%$ & 19.64 to $80.36 \%$ & $50.00 \%$ & 19.64 to $80.36 \%$ & $25.00 \%$ & 10.32 to $49.12 \%$ & $37.50 \%$ & 15.13 to $66.88 \%$ \\
\hline Positive likelihood ratio & 1.71 & 0.90 to 3.25 & 1.71 & 0.90 to 3.25 & 1.64 & 0.86 to 3.11 & 1.69 & 0.89 to 3.21 \\
\hline Negative likelihood ratio & 0.05 & 0.01 to 0.21 & 0.05 & 0.01 to 0.21 & 0.15 & 0.05 to 0.44 & 0.08 & 0.02 to 0.28 \\
\hline Accuracy & $95.21 \%$ & 90.37 to $98.05 \%$ & $95.21 \%$ & 90.37 to $98.05 \%$ & $91.10 \%$ & 85.26 to $95.17 \%$ & $93.84 \%$ & 88.62 to $97.14 \%$ \\
\hline
\end{tabular}

${ }^{\mathrm{a}} \mathrm{Cl}$ confidence interval

absolute cancer risk of the ultra-low-dose CT in this study were lower than those provided by Tabatabaei et al. [18], Dangis et al. [19] and Bahrami-Motlagh et al. [20]. On the other hand, the CTDIvol was higher than that provided by Shiri [24] (0.7 mGy) who used lower $\mathrm{kV}(90 \mathrm{kV})$ and lower pitch (0.8).

The inter-observer agreement in this study was excellent, similar to Tabatabaei et al. [18] and Dangis et al. [19]. The accuracy in this study was also high but did not exceed that of Bahrami-Motlagh et al. (96.6\%) [20]. The CT sensitivity also in this study exceeded that in Azadbakht et al. [25] (60-70\%).

Comparison with Tabatabaei et al. [18], Dangis et al. [19], Bahrami-Motlagh et al. [20] and Shiri [24] regarding the CT protocol parameters as well as the estimated irradiation doses and CT accuracy is demonstrated in Table 6.

The quality of CT images in this study was generally accepted and did not impact the accuracy of CT diagnosis. The SNR of the ultra-low-dose CT in this study even approximated that of the low-dose CT in Kang et al. [6].

The merits of this study over the previous literature were the following: the higher number of included patients compared with previous researches; also the estimation of effective dose, cancer risk, sensitivity and accuracy of the ultra-low-dose CT among two groups of patients with low and high body weight using doubleobserver assessment; and finally the analysis of the CT

Table 6 Comparison between "low-dose" and "ultra-low-dose" CT protocols in this study and previous "low-dose" CT protocols

\begin{tabular}{|c|c|c|c|c|c|c|}
\hline & \multicolumn{4}{|l|}{ Previous studies } & \multicolumn{2}{|l|}{ Current study } \\
\hline & Tabatabaei et al. [17] & Dangis et al. [18] & Bahrami-Motlagh et al. [19] & Shiri et al. [20] & $\begin{array}{l}\text { Routine low } \\
\text { dose }\end{array}$ & $\begin{array}{l}\text { Suggested new } \\
\text { ultra-low dose }\end{array}$ \\
\hline Number of patients & 20 & 192 & 163 & - & 250 & 250 \\
\hline Age (mean) & - & 67 years & - & - & 50 years & 50 years \\
\hline Weight & - & - & - & - & $84 \mathrm{~kg}$ & $84 \mathrm{~kg}$ \\
\hline kV & 120 & 100 & $110-120$ & 90 & 120 & 120 \\
\hline $\mathrm{mA}$ & 30 & 20 & $20-30$ & $20-45$ & 60 & 30 \\
\hline Pitch & 1 & 1.2 & $1.4-1.5$ & 0.8 & 1.4 & 1.4 \\
\hline Rotation time & - & 0.5 & $0.6-0.75$ & - & 0.75 & 0.75 \\
\hline Slice thickness & 3 & - & - & - & 5 & 5 \\
\hline Slice thickness recon & - & 1 & - & - & 1.5 & 1.5 \\
\hline FOV & - & 450 & - & - & 350 & 350 \\
\hline IOA & $98-99 \%$ & $92-98 \%$ & - & - & $100 \%$ & $97-100 \%$ \\
\hline CTDIvol (mGy) & 3.5 & 1.3 & 1.8 & 0.7 & $1.6 \pm 0.4$ & $1.1 \pm 0.3$ \\
\hline DLP (mGy.cm) & 112 & 40 & 65 & - & $60.9 \pm 9.5$ & $42.2 \pm 7.9$ \\
\hline $\begin{array}{l}\text { Mean effective dose } \\
(\mathrm{mSv} / \mathrm{mGy} \mathrm{cm})\end{array}$ & 1.8 & 0.56 & 0.9 & - & 0.85 & 0.59 \\
\hline Absolute cancer risk & $0.74 \times 10^{-4}$ & $0.02 \times 10^{-4}$ & $0.04 \times 10^{-4}$ & - & $0.03 \times 10^{-4}$ & $0.02 \times 10^{-4}$ \\
\hline Accuracy & - & - & $96.6 \%$ & - & $95.21 \%$ & $91.10-93.84 \%$ \\
\hline
\end{tabular}


attenuation in addition to the HRCT findings to determine those with better performance and those with an acceptable percentage of errors.

The study was limited by a short time interval since the beginning of the second wave of the COVID-19 pandemic. The authors encourage further future studies on higher-slice machines to compare the results using filtered back projection (FBP) and iterative dose reduction (IDR).

\section{Conclusion}

Ultra-low-dose HRCT can be reliably used during the second wave of COVID-19 pandemic to reduce irradiation exposure hazards.

\section{Abbreviations}

COVID 19: Coronavirus disease 2019; GGOs: Ground-glass opacities; HRCT: High-resolution computed tomography; RT-PCR: Reverse transcriptionpolymerase chain reaction; DLP: Dose length product; AAPM: American Association of Physicists in Medicine

\section{Acknowledgements}

The authors would like to acknowledge Dr. Engy El-Kady, MD for her effort in data collection and proofreading the manuscript. Also, they would like to acknowledge the radiology technicians who performed the $C T$ examinations, Mr. Mohamed Adel Amin and Mr. Ahmed Mahmoud Arafa.

\section{Authors' contributions}

AS (the corresponding author) is responsible for ensuring that the descriptions are accurate and agreed by all authors. RM, NN and MM had made substantial contributions to all of the following: (1) The conception and design of the radiological work; (2) the acquisition, analysis and interpretation of radiological data; and (3) drafting the work and revising it. RA had made substantial contributions to the acquisition, analysis and interpretation of clinical and laboratory data. Al had made substantial contributions to drafting the work. All authors approved the submitted version. All authors have agreed both to be personally accountable for the author's own contributions and to ensure that questions related to the accuracy or integrity of any part of the work, even ones in which the author was not personally involved, are appropriately investigated, resolved, and the resolution documented in the literature.

\section{Funding}

None (authors' personal contribution)

\section{Availability of data and materials}

The datasets used and/or analyzed during the current study are available from the corresponding author on reasonable request.

\section{Declarations}

\section{Ethics approval and consent to participate}

The medical ethics were considered and respected. The study was approved by the Institutional Ethics Committee in Faculty of Medicine, Alexandria University [IRB No: (00012098), FWA No: (00018699), Serial No: (0304694970)]. Patient verbal consent was obtained. It was approved by the Ethics Committee instead of written consent respecting absolute safety of noninvasive nontherapeutic procedure without additional personal risk or burden to the public health, also assuring full respect of both patient and medical record confidentiality.

\section{Consent for publication}

All patients included in this research gave written informed consent to publish the data contained within this study.

\section{Competing interests}

The authors declare that they have no competing interests.

\section{Author details}

'Department of Radiodiagnosis and Intervention, Faculty of Medicine, University of Alexandria, Alexandria, Egypt. ${ }^{2}$ Ministry of Health and Population, Cairo, Egypt. ${ }^{3}$ Department of Chest Diseases, Faculty of Medicine, Alexandria University, Alexandria, Egypt.

Received: 23 February 2021 Accepted: 11 May 2021

Published online: 26 May 2021

\section{References}

1. McFee RB. Middle East Respiratory Syndrome (MERS) Coronavirus. Disease-aMonth. 2020.

2. Xie X, Zhong Z, Zhao W, Zheng C, Wang F, Liu J (2020) Chest CT for typical 2019-nCoV pneumonia: relationship to negative RT-PCR testing. Radiology 296(2):E41-E45. https://doi.org/10.1148/radiol.2020200343

3. Yang $Y$, Yang $M$, Shen $C$ et al (2020) Evaluating the accuracy of different respiratory specimens in the laboratory diagnosis and monitoring the viral shedding of 2019-nCoV infections. MedRxiv. https://doi.org/10.1101/2020. 02.11 .20021493

4. Mahdavi A, Khalili N, Davarpanah AH et al (2020) Radiologic management of COVID-19: preliminary experience of the Iranian Society of Radiology COVID-19 Consultant Group (ISRCC). Iran J Radiol 17(2). https://doi.org/10. 5812/iranjradiol.102324

5. Wen Z, Chi Y, Zhang L, Liu H, du K, Li Z, Chen J, Cheng L, Wang D (2020) Coronavirus disease 2019: initial detection on chest CT in a retrospective multicenter study of 103 Chinese subjects. Radiol Cardiothorac Imaging 2(2): e200092. https://doi.org/10.1148/ryct.2020200092

6. Kang Z, Li X, Zhou S (2020) Recommendation of low-dose CT in the detection and management of COVID-2019. Eur Radiol 30(8):4356-4357. https://doi.org/10.1007/s00330-020-06809-6

7. Agostini A, Floridi C, Borgheresi A, Badaloni M, Esposto Pirani P, Terilli F, Ottaviani L, Giovagnoni A (2020) Proposal of a low-dose, long-pitch, dualsource chest CT protocol on third-generation dual-source $C T$ using a tin filter for spectral shaping at $100 \mathrm{kVp}$ for coronavirus disease 2019 (COVID19) patients: a feasibility study. Radiol Med 125(4):365-373. https://doi.org/1 0.1007/s11547-020-01179-x

8. Caruso D, Zerunian M, Polici M, Pucciarelli F, Polidori T, Rucci C, Guido G, Bracci B, de Dominicis C, Laghi A (2020) Chest CT features of COVID-19 in Rome, Italy. Radiology 296(2):E79-E85. https://doi.org/10.1148/radiol.20202 01237

9. Kooraki S, Hosseiny M, Myers L, Gholamrezanezhad A (2020) Coronavirus (COVID-19) outbreak: what the department of radiology should know. J Am Coll Radiol 17(4):447-451. https://doi.org/10.1016/j.jacr.2020.02.008

10. American Association of Physicists in Medicine (AAPM) 2019, Lung cancer screening CT protocols version 5.1. https://www.aapm.org/pubs/ CTProtocols/documents/LungCancerScreeningCT.pdf. Accessed 10 Dec 2020.

11. Kubo T, Ohno Y, Nishino M, Lin PJ, Gautam S, Kauczor HU (2016) Study Group. Low-dose chest CT protocol (50 mAs) as a routine protocol for comprehensive assessment of intrathoracic abnormality. Eur J Radiol Open 3:86-94. https://doi.org/10.1016/j.ejro.2016.04.001

12. American Association of Physicists in Medicine. Report No. 096 - the measurement, reporting, and management of radiation dose in CT, 2008.

13. The 2007 Recommendations of the International Commission on Radiological Protection (2007) ICRP publication 103. Ann ICRP 37(2-4):1-332. https://doi.org/10.1016/j.icrp.2007.10.003

14. Sun J, Yu T, Liu J, Duan X, Hu D, Peng Y (2017) Image quality improvement using model-based iterative reconstruction in low dose chest CT for children with necrotizing pneumonia. BMC Med Imaging 17(1):1-8. https:// doi.org/10.1186/s12880-017-0177-9

15. Kim Y, Kim YK, Lee BE, Lee SJ, Ryu YJ, Lee JH, Chang JH (2015) Ultra-lowdose $C T$ of the thorax using iterative reconstruction: evaluation of image quality and radiation dose reduction. AJR 204(6):1197-1202. https://doi. org/10.2214/AJR.14.13629

16. Sookpeng S, Martin CJ, Butdee C (2019) The investigation of dose and image quality of chest computed tomography using different combinations of noise index and adaptive statistic iterative reconstruction level. Indian J Radiol Imaging 29(1):53-60. https://doi.org/10.4103/ijri.IJRI_124_18

17. Xia T, Li J, Gao J, Xu X (2020) Small solitary ground-glass nodule on CT as an initial manifestation of coronavirus disease 2019 (COVID-19) pneumonia. Korean J Radiol 21(5):545-549. https://doi.org/10.3348/kjr.2020.0240 
18. Tabatabaei SM, Talari H, Gholamrezanezhad A et al (2020) A low-dose chest CT protocol for the diagnosis of COVID-19 pneumonia: a prospective study. Emerg Radiol 27(6):607-615. https://doi.org/10.1007/s10140-020-01838-6

19. Dangis A, Gieraerts C, Bruecker YD et al (2020) Accuracy and reproducibility of low-dose submillisievert chest CT for the diagnosis of COVID-19. Radiol Cardiothorac Imaging 2(2):e200196. https://doi.org/10.1148/ryct.2020200196

20. Bahrami-Motlagh H, Abbasi S, Haghighimorad M, Salevatipour B, Alavi Darazam I, Sanei Taheri M, Esmaeili Tarki F, Naghibi Irvani SS (2020) Performance of low-dose chest CT scan for initial triage of COVID-19. Iran J Radiol 17(4):e104950. https://doi.org/10.5812/iranjradiol.104950

21. Mohammad SA, Osman AM, Abd-Elhameed AM et al (2020) The battle against Covid-19: the experience of an Egyptian radiology department in a university setting. Egypt J Radiol Nucl Med 51(1):1-9

22. Chung M, Bernheim A, Mei X, Zhang N, Huang M, Zeng X, Cui J, Xu W, Yang Y, Fayad ZA, Jacobi A, Li K, Li S, Shan H (2020) CT imaging features of 2019 novel Coronavirus (2019-NCOV). Radiology 295(1):202-207. https://doi. org/10.1148/radiol.2020200230

23. Song F, Shi N, Shan F, Zhang Z, Shen J, Lu H, Ling Y, Jiang Y, Shi Y (2020) Emerging 2019 novel Coronavirus (2019-NCOV) pneumonia. Radiology 295(1):210-217. https://doi.org/10.1148/radiol.2020200274

24. Shiri I, Akhavanallaf A, Sanaat A, Salimi Y, Askari D, Mansouri Z, Shayesteh SP, Hasanian M, Rezaei-Kalantari K, Salahshour A, Sandoughdaran S, Abdollahi H, Arabi H, Zaidi H (2021) Ultra-low-dose chest CT imaging of COVID-19 patients using a deep residual neural network. Euro Radiol 31(3): 1420-1431. https://doi.org/10.1007/s00330-020-07225-6

25. Azadbakht J, Khoramian D, Lajevardi ZS et al (2021) A review on chest CT scanning parameters implemented in COVID-19 patients: bringing low-dose CT protocols into play. Egypt J Radiol Nucl Med 52(1):1-0

\section{Publisher's Note}

Springer Nature remains neutral with regard to jurisdictional claims in published maps and institutional affiliations.

\section{Submit your manuscript to a SpringerOpen ${ }^{\circ}$ journal and benefit from:}

- Convenient online submission

- Rigorous peer review

- Open access: articles freely available online

- High visibility within the field

- Retaining the copyright to your article

Submit your next manuscript at $\boldsymbol{\nabla}$ springeropen.com 